\title{
Low prevalence of the molecular markers of Plasmodium falciparum resistance to chloroquine and sulphadoxine/pyrimethamine in asymptomatic children in Northern Benin
}

\author{
Aurore Ogouyèmi-Hounto ${ }^{1,2^{*}}$, Nicaise Tuikue Ndam ${ }^{3,4}$, Gildas Fadégnon ${ }^{2}$, Carmine Azagnandji2, \\ Mourchidath Bello², Azizath Moussiliou ${ }^{3,4}$, Jean-Phillipe Chippaux ${ }^{4}$, Dorothée Kinde Gazard ${ }^{1,2}$ \\ and Achille Massougbodji ${ }^{1,2}$
}

\begin{abstract}
Background: In Benin, very few studies have been done on the genetics of Plasmodium falciparum and the resistance markers of anti-malarial drugs, while malaria treatment policy changed in 2004. Chloroquine (CQ) and sulphadoxine pyrimethamine (SP) have been removed and replaced by artemisinin-combination therapy (ACT). The objective of this study was to determine the genetic diversity of $P$. falciparum and the prevalence of $P$. falciparum molecular markers that are associated with resistance to $C Q$ and SP in northern Benin seven years after the new policy was instituted.

Methods: The study was conducted in northern Benin, a region characterized by a seasonal malaria transmission. Blood samples were collected in 2012 from children presenting with asymptomatic $P$. falciparum infections. Samples collected in filter paper were genotyped by primary and nested PCR in block 2 of $m s p-1$ and block 3 of $m s p-2$ to analyse the diversity of $P$. falciparum. The prevalence of critical point mutations in the genes of Pfcrt (codon 76), Pfmdr1 (codon 86), Pfdhfr (codons, 51, 59 and 108) and Pfdhps (codons 437, 540) was examined in parasite isolates by mutation-specific restriction enzyme digestion.

Results: Genotyping of 195 isolates from asymptomatic children showed 34 msp-1 and 38 msp-2 genotypes. The multiplicity of infection was $4.51 \pm 0.35$ for $m s p-1$ and $4.84 \pm 0.30$ for msp-2. Only the codon 51 of Pfdhfr and codon 437 of Pfdhps showed a high mutation rate: 151: 64.4\% (57.3; 71.2); G437: 47.4\% (40.2; 54.7), respectively. The prevalence of Pfdhfr triple mutant IRN (I51, R59 and N108) was 1.5\% (0.3; 3.9), and Pfdhfr/Pfdhps quadruple mutant IRNG (Pfdhfrl51, R59, N108, and PfdhpsG437): 0. 5\% (0; 2.5). No mutation was found with codon 540 of Pfdhps. Analysis of mutation according to age (younger or older than ten years) showed similar frequencies in each category without significant difference between the two groups.
\end{abstract}

Conclusions: This study showed a high diversity of $P$. falciparum in northern Benin with a very low prevalence of resistance markers to $C Q$ and SP that dramatically contrasted with the pattern observed in southern Benin. No influence of age on genetic diversity of $P$. falciparum and on distribution of the mutations was observed.

Keywords: Plasmodium falciparum, Genotyping, Resistance, Mutation, Chloroquine, Sulphadoxine-pyrimethamine

\footnotetext{
* Correspondence: aurorefel@yahoo.fr

'Unité d'Enseignement et de Recherche en Parasitologie Mycologie de la

Faculté des Sciences de la Santé, 01 BP188, Bénin

${ }^{2}$ Laboratoire du Centre de Lutte Intégrée contre le Paludisme, Cotonou 01

BP188, Bénin

Full list of author information is available at the end of the article
} 


\section{Background}

Malaria is one of the killer diseases in the world and particularly in sub-Saharan Africa where $90 \%$ of deaths due to malaria are recorded [1]. In Benin, Plasmodium falciparum infections are among the leading causes of disease and are also $36 \%$ of cause of death among children under five years (unpublished data from Ministry of Health). Despite intensification of control methods against malaria, multiple factors, including insecticide resistance in anopheline vectors and the emergence and rapid spread of drug-resistant strains, remain of major concern in efforts to control and prevent malaria. In this context, adequate vaccine development is a big challenge in malaria control. However, this approach is complicated by genetic diversity of $P$. falciparum as it influences the acquisition of protective immunity to malaria. Asexual blood stage antigens, such as merozoite surface protein-1 (msp-1) and merozoite surface protein-2 (msp-2) are considered prime candidates for the development of malaria vaccine and are also suitable markers for the identification of genetically distinct $P$. falciparum parasite subpopulations [2]. These two genes are also the basis for determining the multiplicity of infection (MOI) in infected individuals, which is a good indicator of acquired immunity or premunition of populations living in endemic areas, and is also correlated to transmission intensity $[3,4]$.

Following the change of malaria policy treatment in Benin in 2004 with the replacement of chloroquine (CQ) and sulphadoxine pyrimethamine (SP), the first- and second-line treatment, by artemisinin combination therapy (ACT) for the treatment of uncomplicated malaria, drug pressure with these molecules has since been reduced. Unlike in Malawi [5,6], a study performed in southern Benin [7] revealed high rates of resistant genotypes in genes $\mathrm{P} f c r t$, Pfmdrl, Pfdhfr, and Pfdhps. Although SP is still used in intermittent preventive treatment in pregnancy (IPTp) as recommended by WHO, recent observation of such high rates of resistant parasite mutants suggested that despite the official withdrawal of CQ and SP from the treatment of uncomplicated malaria, these drugs were still used in Benin.

Parakou is a semi-urban city situated in the north of the Republic of Benin and has been well characterized as a highly endemic area with seasonal malaria transmission. However, there is no information on the genetic diversity of $P$. falciparum populations regarding resistance markers in this area. The present study was conducted in this locality to determine: (i) the genetic diversity of $P$. falciparum based on the $m s p-1$ and $m s p-2$ polymorphism; and, (ii) the prevalence of $P$. falciparum molecular markers that are associated with resistance to CQ and SP by analysing the point mutations in Pfcrt, Pfmdr1, Pfdhfr and Pfdhps gene using samples from asymptomatic children in northern Benin.

\section{Methods}

\section{Study sites and population}

The study was conducted in the city of Parakou, a municipality in the north of Benin. It is the largest semiurban city in northern Benin with 188,853 inhabitants. In the north, transmission occurrs from June to October during the rainy season and is spread by Anopheles gambiae s.s. (85\%) and Anopheles arabiensis (15\%) [8]. Children aged two to 15 years, asymptomatic and permanent residents of the study area, were enrolled from May to September 2012 from nursery and primary schools. The recruitment of these children has been described elsewhere [7]. Inclusion criteria were: i) axillary temperature $<37.5^{\circ} \mathrm{C}$; ii) absence of fever in the previous two weeks and at least one week after enrolment; and, iii) positive thick smear regardless of parasite density.

\section{Collection and handling of blood samples}

Thick and thin blood smears were prepared from venous blood, stained with $10 \%$ Giemsa for rapid diagnosis and were examined against 500 leucocytes. Parasite densities were recorded as the number of parasites/ $\mu \mathrm{l}$ of blood assuming an average leucocyte count of $8,000 / \mu \mathrm{l}$ of blood. For samples containing parasites, four separate drops of blood were spotted and stored on to Whatman 3 filter paper for further DNA extraction. All slides were read in the health centre's laboratory with external quality control of $10 \%$ of the negatives slides and all positives in the Reference Laboratory of Parasitology of the Centre National Hospitalier Universitaire of Cotonou. Suspected malaria patients, following microscopy results, were treated according to malaria treatment policy based on ACT: artemether-lumefantrine. Parasite DNA was extracted from filter papers using the Chelex100 resin methods [9] and stored at $-20^{\circ} \mathrm{C}$ until use.

\section{Molecular genotyping of the polymorphic genes msp-1 and msp-2}

Specific primer pairs were used to amplify block 2 of $m s p$ 1 and block 3 of $m s p-2[10,11]$. The two genes were amplified by primary and nested PCR, each amplification with conserved or family-specific primer pairs being done separately, as described previously [12]. Analysis of the 3D7 and FC27 allelic families of $m s p-2$ and the K1, MAD20 and RO33 allelic families of $m s p-1$ were sequentially performed in accordance with the genotyping protocol of Snounou et al. [12]. Allelic-specific positive controls and DNA-free negative controls were included in each set of reaction. Gel photographs were re-scored by visual comparison of DNA fragments and for individual samples, alleles were identified according to band size and the corresponding allele-specific primers used. The size of the PCR products was estimated using a $100 \mathrm{bp}$ DNA ladder marker (Boehringer Mannheim, Marker VI). 
PCR amplification of Pfcrt, Pfmdr, Pfdhfr and Pfdhps genes and detection of Single nucleotide polymorphisms (SNPs)

Parasite DNA was amplified with outer and nested specific primers targeting the Pfcrt, Pfmdr1, Pfdhfr and Pfdhps genes, as described [13-15]. The Single nucleotide polymorphisms in the various gene targets were detected using the Restriction Fragment Length Polymorphism (RFLP) technique previously reported by Ogouyemi Hounto et al. [7]. The molecular analyses were performed in the Molecular Biology Laboratory of the Centre de Lutte integrée contre le Paludisme.

\section{Data analysis}

The data were entered in the software $\mathrm{R}$ version 2.12.0 (R Foundation for Statistical Computing, Vienna, Austria). The distribution of allelic families of $m s p-1$ and $m s p-2$ genes was determined by the number of PCR products corresponding to each family within the total number of samples. The number of patients with more than one amplified PCR fragment within the total population is defined as the frequency of polyclonal infections. The MOI was determined as the number of different $m s p-1$ and $m s p-2$ genotypes per isolate, and the mean MOI was calculated as the total number of detected $P$. falciparum msp-1, $m s p-2$ genotypes/total number of infected children [16]. Each codon was characterized as wild type (no mutation present), pure mutant (only mutant genotypes detected). Cases of mixed infection (wild type and mutant) were categorized as mutant throughout the analysis. The frequency of a particular mutant was calculated as the proportion of the specific mutant samples among the total number of samples successfully analysed for this mutation. Similarly, the frequencies of double, triple and quadruple mutants were determined as the proportion of subjects with two, three and four mutations among the total numbers of samples tested for the each. To investigate the relationship between the mutation, MOI and age, children were segregated into two categories: children below and above ten years of age. This grouping resulted from recent intensification of malaria control activities in the country, such as the widespread distribution and use of insecticide-treated nets and large-scale indoor spraying of residual insecticides, which are likely to delay the age of acquisition of immunity, usually occurring at five years in endemic areas [17]. In areas where malaria transmission is seasonal, the acquisition of immunity is later than in the areas with perennial transmission. Student's test was used to compare MOI. The Chisquare test or Fisher's exact test was used for proportion comparisons. The $\mathrm{p}$ value $<0.05$ was chosen as threshold significance for the various statistical tests.

\section{Ethical approval}

This study obtained the ethical approval of the National Ethics Committee for Health Research of Benin.

\section{Results}

\section{Demographic and parasitological data of the study} population

During five months, 1,642 asymptomatic children were screened, from which 214 positive samples for $P$. falciparum were collected on filter paper. The prevalence of asymptomatic parasitaemia detected by microscopy was 13\%, P. falciparum being the only infecting Plasmodium species found. After the withdrawal of children above 15, 195 samples were selected for molecular analysis.

Characteristics of the study population are detailed in Table 1. Children's ages ranged from two to 15 years (mean age: $7.9 \pm 0.4$ years). The parasite density ranged from 12 to 86,570 parasites/ $\mu \mathrm{l}$ with a geometric mean density of 209.6 (161.2-272.5).

The parasite DNA from the 195 P. falciparum isolates were analysed for $m s p-1$ and $m s p-2$ genes. The efficiency of $m s p-1$ and $m s p-2$ genes amplification reactions with family-specific primers was 99\% (193/195) and 99.5\% (194/195), respectively.

Regarding the analysis of the mutation, the number of isolates depended on the success of PCR amplification and was 195 for Pfcrt (100\%), 193 (99\%) for Pfmdr1, 192 (98.5\%) for Pfdhps and 194 (99.5\%) for Pfdhfr. Samples that were retested to check the reproducibility of results were consistent with those found initially.

\section{Genetic diversity of Plasmodium falciparum msp- 1 and msp-2 gene}

A total of 72 individual $m s p$ alleles were identified (34 for $m s p-1$ and 38 for $m s p-2)$. The K1 family was the predominant allelic type among monoclonal infections (17.1\%), in mixed infection with Mad20 (13.5\%) and RO33 (11.9\%). This family was also more represented $(\mathrm{p}<0.01)$ in overall population (90.7\%). Mad20 and Ro33 families were found respectively in 67.4 and $66.8 \%$ of isolates. For $m s p-2$ gene, the FC27 family was more represented but not statistically significant $(\mathrm{p}=0.57)$. The distribution of

Table 1 Demographic and parasitological data of the study population

\begin{tabular}{ll}
\hline Characteristics of patients & Values \\
\hline Mean age (year) & $7.9 \pm 0.4$ \\
Age range (year) & $2-15$ \\
Sex ratio $(M / F)$ & $1.03(99 / 96)$ \\
Microscopy $P$. falciparum prevalence, 214/1,642 & $13 \%$ \\
Geometric mean parasite density $(\mathrm{p} / \mu \mathrm{l})$ & $209.6(161.2-272.5)$ \\
Parasite density range $(\mathrm{p} / \mu \mathrm{l})$ & $12-86,570$ \\
\hline
\end{tabular}


the different allelic families of $m s p-1$ and $m s p-2$ genes is shown in Additional file 1: Table S1.

The number of $m s p-1$ and $m s p$ - 2 genotypes per isolate ranged from one to 11 . MOI was $4.51 \pm 0.35$ for $m s p-1$ and $4.8 \pm 0.30$ for $m s p-2$. According to age, MOI was $4.8 \pm 0.43$ in children below ten and $4.1 \pm 0.59$ in older children with $m s p-1$ gene $(\mathrm{p}=0.06)$. Regarding $m s p-2$ gene, MOI was $4.3 \pm 0.46$ and $3.9 \pm 0.60$, respectively, in children below ten and older children, respectively, $\mathrm{p}=$ 0.18 . Multiple infections were found in $71.5 \%(138 / 193)$ for $m s p-1$ and $91.7 \%(178 / 194)$ for $m s p-2$.

\section{Prevalence of Pfcrt and Pfmdr1, alleles and mutations}

The wild type alleles K76 and N86 of Pfcrt and Pfmdr1 gene, respectively, were present in $71.3 \%$ (139/195) and $75.6 \%(146 / 193)$ of samples from patients that were analysed, whereas mutant and mixed alleles were poorly represented (Figure 1). Thus, prevalence of T76 mutation was $28.7 \%(56 / 193)(22.5 ; 35.6)$, while Y86 was found in $24.4 \%(47 / 193)(18.5 ; 31.0)$ (Table 2).

\section{Prevalence of Pfdhps and Pfdhfr allelic forms Pfdhps}

At codon 437, the wild type allele A437 (52.6\%: 101/ 192) was more represented in the population than mutant (G437: 24.5\%: 47/192) and mixture of alleles (A437/G437: 22.9\%: 44/192), P < 0.01. However, all samples carried the wild type allele K540 of codon 540 and no mutation E540 was found (Figure 2, Table 2). Overall, mutation of codon 437 (G437) was found in 47.4\% (40.2; 54.7) of the samples analysed (91/192).

\section{Pfdhfr}

Except for codon 51 in which mutated alleles were more represented (I51: 55,7\%: 108/194), the analysis of other codons showed high prevalence of wild type alleles. Allele C59 were found in $74.2 \%$ of the samples (144/194) and S108 in 82\% (159/194) (Figure 3). Thus, a high prevalence of mutant genotypes was observed only at codon 51 (I51: $64.4 \%(125 / 194)(57.3 ; 71.2))$ compared to other codons

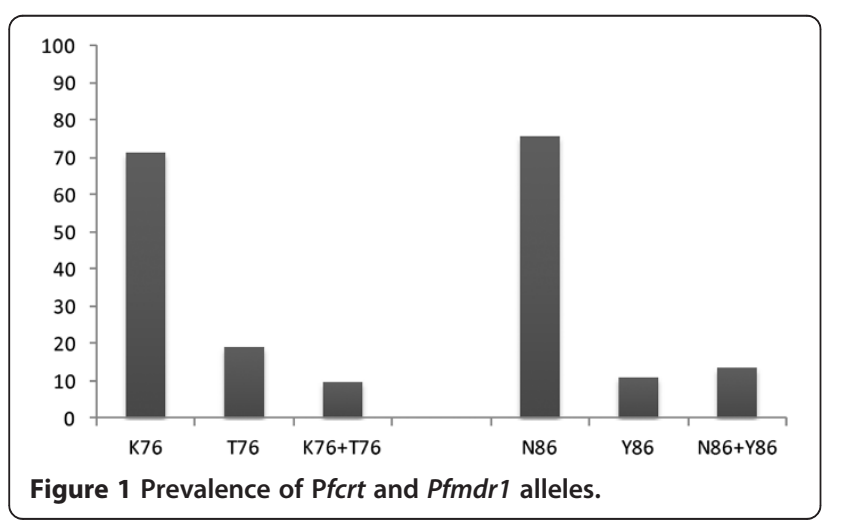

Table 2 Prevalence of molecular markers associated with Plasmodium falciparum resistance to chloroquine and sulphadoxine-pyrimethamine in study population according to age

\begin{tabular}{lllll}
\hline $\begin{array}{l}\text { Molecular } \\
\text { marker }\end{array}$ & $\mathbf{n}(\%)$ & $\begin{array}{l}<\mathbf{1 0} \text { years } \\
\mathbf{n}(\%)\end{array}$ & $\begin{array}{l}\geq \mathbf{1 0} \text { years } \\
\mathbf{n}(\%)\end{array}$ & $\begin{array}{l}\mathbf{P} \\
\text { value }\end{array}$ \\
\hline T76 $(n=195)$ & $56(28.7)$ & $38(31.1)$ & $18(24.7)$ & 0.42 \\
Y86 $(n=193)$ & $47(24.4)$ & $26(22)$ & $21(28)$ & 0.44 \\
T76Y86 $(n=193)$ & $10(4.6)$ & $6(4.4)$ & $4(4.8)$ & 1.00 \\
G437 $(n=192)$ & $91(47.4)$ & $56(47.5)$ & $35(47.3)$ & 0.90 \\
E540 $(n=192)$ & $0(0)$ & $0(0)$ & $0(0)$ & \\
I51 $(n=194)$ & $125(64.4)$ & $76(61.8)$ & $49(69)$ & 0.39 \\
R59 $(n=194)$ & $50(25.8)$ & $29(24.2)$ & $21(28.4)$ & 0.63 \\
N108 $(n=194)$ & $35(18)$ & $24(20.2)$ & $11(14.7)$ & 0.44 \\
IRN $(n=194)$ & $3(1.5)$ & $1(0.7)$ & $2(2.4)$ & 0.56 \\
IRNG (192) & $1(0.5)$ & 0 & $1(1.2)$ & 0.38 \\
\hline
\end{tabular}

where the prevalence of mutants remained very low (R59: 25.8\% (50/194) (19.8; 32.5), N108: 18\% (35/194) (12.9; 24.2)) ( $<$ 0.01). Combined analysis of the different Single nucleotide polymorphisms revealed that the prevalence of Pfdhfr triple mutant IRN (I51, R59 and N108) and Pfdhfr/ Pfdhps quadruple mutant IRNG (Pfdhfr I51, R59, N108, and PfdhpsG437) was actually very low: IRN: $1.5 \%(3 / 194)$ (0.3; 3.9), IRNG: 0.5\% (1/192) $(0 ; 2.5)$ (Table 2).

\section{Mutation and age}

When the data were analysed by age categories, similar frequencies of single, triple and quadruple mutant parasite were found in children younger than ten years and in older children (Table 2).

\section{Mutation and polyclonality}

The analysis showed similar frequency of single, double, triple and quadruple mutation in monoclonal and polyclonal infections regardless of the gene (msp-1 or $m s p-2)$.

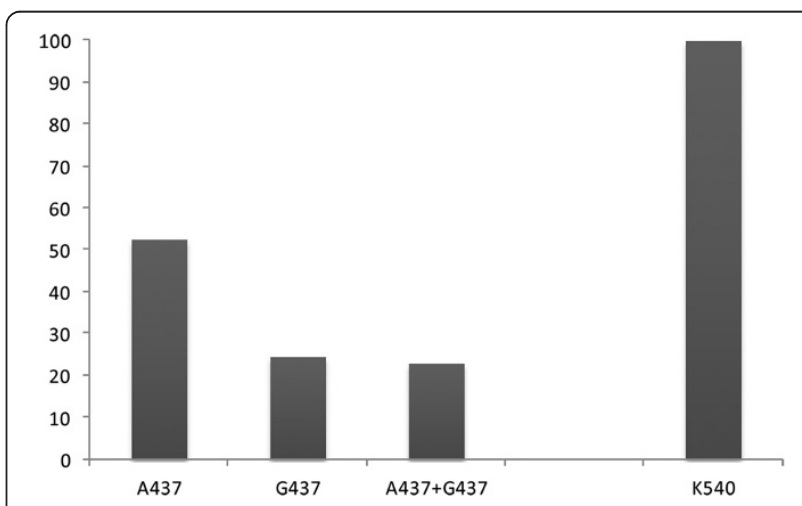

Figure 2 Prevalence of pfdhps alleles. 


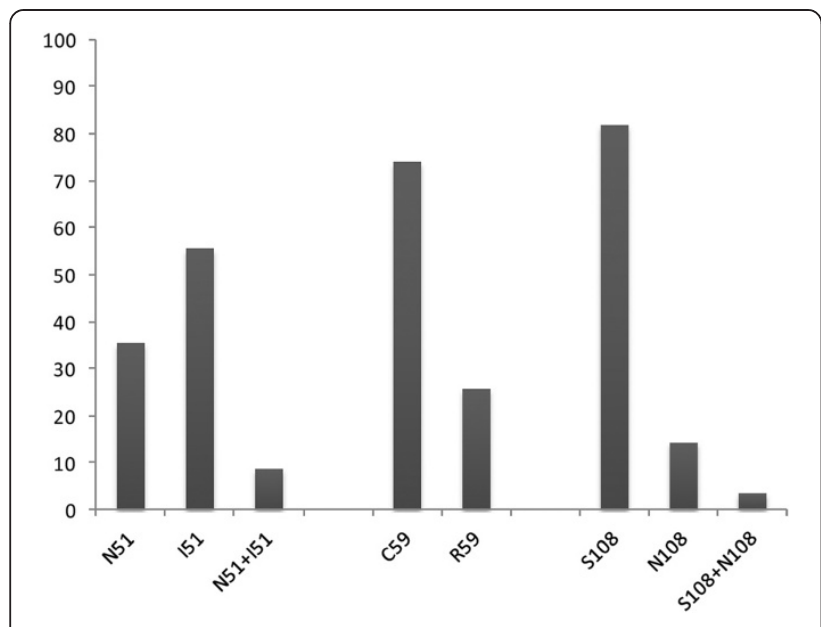

Figure 3 Prevalence of Pfdhfr alleles.

However, the mutation G437 seemed to be more represented in polyclonal infections of $m s p-1$ gene (Table 3 ).

\section{Discussion}

In the Republic of Benin, less attention had been put on the investigation of the genetic diversity of $P$. falciparum and on the molecular markers of $P$. falciparum resistance to $\mathrm{CQ}$ and SP since the change of malaria treatment policy in 2004. The purpose of this study was to determine the genetic diversity of $P$. falciparum using the two most polymorphic regions of $m s p-1$ and $m s p-2$ genes, and the prevalence of molecular markers of $P$. falciparum to CQ and SP in malaria asymptomatic subjects in northern Benin. This analysis intends to develop efficient strategies for malaria control, and improve the surveillance of the actual level of $P$. falciparum resistance to anti-malarial drugs in Benin.
This study follows a previous one that was conducted in southern Benin [7]. Allele-specific genotyping of $m s p-1$ and $m s p-2$ showed a high genetic diversity in the $P$. falciparum population studied in Parakou with a MOI of 4.5 (msp-1) and 4.8 (msp-2). This figure is similar to that observed in southern Bénin (unpublished data). Actually, a minimum of 34 alleles of $m s p-1$ were observed, in which the $\mathrm{K} 1$ allelic family was predominant, consistent with the previous study [18-21] but in contrast to Barty [22] in India showing that RO33 family was predominant. For the $m s p-2$ locus, 38 alleles were found and alleles belonging to FC27 family were mostly detected, both in mono-infection and mixed infection with 3D7 alleles. Although this is similar to data reported in Congo [23], it differs from previous results of Issifou et al. in south Benin [19], and Mayengue et al. in Congo Brazzaville [24]. The difference with the results of Issifou et al. may be due to the fact that the study goes far back in the past. Indeed, according Yuang et al. in Myanmar [25], the majority of alleles showed significant temporal fluctuations through the years. The high rate of multiple infections of $P$. falciparum infections with $m s p-1$ and $m s p-2$ found elsewhere $[16,26]$ would probably be a consequence of intense malaria transmission of study areas. Actually, the mean MOI was high compared to those reported in Benin, Burkina Faso, Congo Brazzaville $[18,19,24]$, but consistent those from Gabon and Senegal [20,27]. The high rate of MOI in the present study suggests that, despite the intensification of malaria control interventions involving reduction of malaria infections, the parasite population size and transmission intensity remained high enough to allow effective genetic recombination of the parasites and continued maintenance of genetic diversity. The fact that MOI was not influenced by age as shown in other countries [28,29] suggests that the MOI is not directly related to the period

Table 3 Mutation and polyclonality

\begin{tabular}{|c|c|c|c|c|c|c|}
\hline \multirow[t]{2}{*}{ Mutations } & \multicolumn{3}{|c|}{ Msp-1 $(\mathrm{n}=193)$} & \multicolumn{3}{|c|}{$M s p-2(\mathrm{n}=194)$} \\
\hline & $\begin{array}{l}\text { Monoclones } \\
\text { n (\%) }\end{array}$ & $\begin{array}{l}\text { Polyclones } \\
\text { n (\%) }\end{array}$ & $\begin{array}{l}\text { p-value } \\
\text { n (\%) }\end{array}$ & $\begin{array}{l}\text { Monoclones } \\
\text { n (\%) }\end{array}$ & Polyclones & $p$-value \\
\hline & $n=55$ & $\mathrm{n}=138$ & & $n=16$ & $\mathrm{n}=178$ & \\
\hline & n (\%) & n (\%) & & n (\%) & n (\%) & \\
\hline T76 & $19(34.5)$ & $37(26.8)$ & 0.10 & $6(37.5)$ & $50(28.1)$ & 0.39 \\
\hline Y86 & $9(16.4)$ & $38(27.5)$ & 0.40 & $1(6.3)$ & $46(25.8)$ & 0.23 \\
\hline T76Y86 & $5(9.1)$ & $5(3.6)$ & 0.13 & 0 & $10(5.6)$ & 0.78 \\
\hline G437 & $14(25.5)$ & $77(55.8)$ & 0.01 & $6(37.5)$ & $85(47.7)$ & 0.96 \\
\hline 151 & $31(56.4)$ & $94(68.1)$ & 0.48 & $8(50.0)$ & $117(65.7)$ & 0.77 \\
\hline R59 & $15(27.3)$ & $35(25.4)$ & 0.44 & $2(12.5)$ & $48(27)$ & 0.49 \\
\hline N108 & $10(18.2)$ & $25(18.1)$ & 0.74 & $1(6.3)$ & $34(19.1)$ & 0.46 \\
\hline IRN & $2(3.6)$ & $1(0.7)$ & 0.07 & 0 & $3(1.7)$ & 1.00 \\
\hline IRNG & $1(1.8)$ & 0 & 0.56 & 0 & $1(0.6)$ & 1.00 \\
\hline
\end{tabular}


of acquisition of immunity in asymptomatic children, but reflects the exposure of subjects to malaria in endemic area.

The major finding of this study is that analysis of wellcharacterized molecular markers of $P$. falciparum resistance to CQ and SP, two anti-malarials that have long been used in the treatment of uncomplicated malaria in Benin, revealed contrasted low prevalence of resistant genotypes in northern Benin as opposed to the south [7]. A low prevalence of T76 (28.7\%) mutation associated with resistance to CQ was observed in this study compared to the study carried out in the south in 2011 where a high prevalence of this mutation was observed, indicating a persistence of resistance to CQ seven years after the change of malaria treatment policy. The same goes for the quadruple mutation associated with resistance to SP, which is very low in this setting compared to data reported in southern Benin. The dramatic difference between the results could be explained by a higher drug pressure in southern Benin. Parakou is a semiurban city $407 \mathrm{~km}$ from Cotonou in the north of the country where self-medication and a parallel market for counterfeit drugs are lower than in the south, where proximity to Nigeria promotes drug traffic and pressure. Duah et al. in Ghana [30] observed an increase of drugresistant genotypes in the urban setting compared to rural areas. Some studies [31,32] have shown the selection of sensitive phenotypes of Pfcrt and Pfmdr1 gene after stopping the use of $C Q$ and extending the use of the AL. Data in southern Benin where the policy change was made at the same time does not show this reversion and still is an extremely high prevalence of pfcrt and Pfmdr1 mutants [7]. However, the likely effect of the introduction of artemether-lumefantrine in the explanation of this phenomenon, which may be even more pronounced in areas where the pressure is lower like north Benin can be taken into account.

The migration of parasites related to population movements between the north and south of Benin could increase the prevalence of resistant parasites. However the inclusion of children living in Parakou for at least six months has probably allowed the minimizing of such a risk. This does not preclude transmission of resistant parasites by mosquito bites on persons in transit harbouring resistant parasites. Certainly the magnitude of this phenomenon is minimal and not enough to significantly increase the proportion of resistant parasites.

As malaria treatment policy was harmonized in the country when policy change was decided in 2004, it had not been taken into account places where low rates of treatment failure had been noted. Indeed, in Parakou in 2002, in vivo efficacy studies conducted according to WHO protocol [33] reported $13.9 \%$ of treatment failure with CQ (4.6 and 9.3\% early and late treatment failures, respectively), which was lower compared to the national average of $35.2 \%$ treatment failure (unpublished data from NMCP of Ministry of Health). Based on the association between treatment failure to $C Q$ and the prevalence of T76 mutation [13,34], the results in this study rather suggest the existence of a small proportion of mutation T76 before the policy change. This also suggests that the low prevalence observed in this study is unlikely to result from the re-emergence of susceptible strains related to the reduction of drug pressure.

Regarding SP, the therapeutic failure rates observed in 2002 in Parakou were 3.3\% (1.6 and 1.7\% early and late treatment failures, respectively) against the $22.8 \%$ national average. Given the relation between triple Pfdhfr mutations, double Pfdhps mutations and clearance of parasitaemia after SP treatment [35-37], the very low rates of parasite with quadruple Pfdhfr Pfdhps mutant (IRNG: $0.5 \%$ ) found in this study, suggests that there was very little parasite resistance to SP in the study area before the withdrawal of the drug from the treatment of uncomplicated malaria in 2004. In this study, the high mutation rates on codon 51 quite surprising, which almost twice the level in the codon 108 mutation was observed. There is no logical explanation for this, but in some studies mutation rates of codon 51 and 108 appeared to be substantially the same as described by Dicko et al. [38], and the selection of mutants could be faster with the codon 51. It is likely that the use of SP in IPTp did not contribute to an increase in the rate of resistant parasites, in agreement with studies reported in Senegal and Mali $[38,39]$. The data generated in this study suggest that these two molecules could still be used in the treatment of malaria in Parakou, however, the difficulty in policy management of malaria in the country argues for a harmonized strategy.

The proportion of infections by parasites carrying specific mutations between children younger than ten years and older children suggests that age does not influence the distribution and carriage of resistant parasites whatever the type of mutation, as shown elsewhere $[7,40]$. To investigate whether the mutation patterns were influenced by polyclonality, the parasite isolates were classified as monoclonal and polyclonal. Apart from the G437 mutation, which was more prevalent in polyclonal infections, all other mutations: single, double, triple or quadruple, were distributed similarly in both groups regardless of the gene. These results suggest that the number of clones is not directly involved in the carriage of mutant parasites. However, it would be interesting to investigate the link between polyclonality and mutation in a population with high prevalence of mutation in order to draw better conclusions.

\section{Conclusions}

This study showed a high diversity of $P$. falciparum in northern Benin irrespective of age in asymptomatic 
children. It also highlighted a low prevalence of markers of parasite resistance to CQ and SP, indicating that most $P$. falciparum strains are still potentially sensitive to these molecules in this part of the country. These results strongly opposed to those in the south which shows the need to map molecular markers of resistance in different regions of endemic countries, taking into account the drug pressure.

\section{Consent}

All parents or guardians of children gave their informed consent to participate in the study and the possible use of the data for publication.

\section{Additional file}

Additional file 1: Table S1. Genetic diversity of $P$. falciparum $m s p-1$ and $m s p-2$ gene.

\section{Competing interests}

The authors declare that they have no competing interests.

\begin{abstract}
Authors' contributions
DKZ designed the study protocol, supervised the study and corrected the manuscript; $\mathrm{AOH}$ participated in the design of study, supervised the study and laboratory examinations, drafted the manuscript; NTN supervised laboratory examinations, monitored laboratory quality assurance and participated in manuscript writing; GF, CA, MB, and AM assured patients' enrolment, molecular analysis and participated in manuscript writing; JPC coordinated and helped to draft the manuscript. AM participated in the design of the study, coordination and helped to draft the manuscript. All authors read and approved the final manuscript.
\end{abstract}

\section{Acknowledgements}

We are grateful to the children who participated in the study, as well as to their mothers and head of their schools. We are pleased to thank caregivers, laboratory workers from IRD and the National Malaria Control Programme. This work was financed by French Development Agency and Benin Ministry of Health. This funding has contributed to data collection, laboratory testing and statistical analysis.

\section{Author details}

${ }^{1}$ Unité d'Enseignement et de Recherche en Parasitologie Mycologie de la Faculté des Sciences de la Santé, 01 BP188, Bénin. ${ }^{2}$ Laboratoire du Centre de Lutte Intégrée contre le Paludisme, Cotonou 01 BP188, Bénin. ${ }^{3}$ PRES Sorbonne Paris Cité, Faculté de Pharmacie, Université Paris Descartes, France. ${ }^{4}$ Institut de Recherche pour le Développement, UMR216 Mère et enfant face aux infections tropicales, Cotonou 08 BP 841, Bénin.

Received: 12 June 2013 Accepted: 10 November 2013

Published: 13 November 2013

\section{References}

1. World Health Organization: World malaria report 2010. http://www.who.int/ malaria/world_malaria_report_2010/worldmalariareport2010.pdf.

2. Ekala MT, Jouin H, Lekoulou F, Issifou S, Mercereau-Puijalon O, Ntoumi F: Plasmodium falciparum merozoite surface protein 1 (msp-1): genotyping and humoral responses to allele-specific variants. Acta Trop 2002, 81:33-46.

3. Babiker HA, Ranford-Cartwright LC, Walliker D: Genetic structure and dynamics of Plasmodium falciparum infections in the Kilombero region of Tanzania. Trans R Soc Trop Med Hyg 1999, 93:11-14.

4. Smith T, Beck HP, Kitua A, Mwankusye S, Feldrl I, Fraser-Hurt N, Irion A, Alonso P, Teuscher T, Tanner M: Epidemiology of multiple Plasmodium falciparum infections. Age dependence of the multiplicity of Plasmodium falciparum infections and other malariological indices in an area of high endemicity. Trans R Soc Trop Med Hyg 1999, 93:15-20.
5. Kublin JG, Cortese JF, Njunju EM, Mukadam RA, Wirima JJ, Kazembe PN, Djimdé AA, Kouriba B, Taylor TE, Plove CV: Re-emergence of chloroquinesensitive Plasmodium falciparum malaria after cessation of chloroquine use in Malawi. J Infect Dis 2003, 187:1870-1875.

6. Laufer MK, Thesing PC, Eddington ND, Masonga R, Dzinjalamala FK, Takala SL, Taylor TE, Plowe CV: Return of chloroquine antimalarial efficacy in Malawi. N Engl J Med 2006, 355:1959-1966.

7. Ogouyèmi-Hounto A, Tuikue Ndam N, Kinde Gazard D, D'Almeida S, Koussihoude L, Ollo E, Azagnandji C, Bello M, Chippaux JP, Massougbodji A: Prevalence of the molecular markers of Plasmodium falciparum resistance to chloroquine and sulphadoxine/pyrimethamine in Benin seven years after the change of malaria treatment policy. Malar J 2013, 12:147.

8. Yadouléton A, N'Guessan R, Allagbé H, Asidi A, Boko M, Osse R, Padonou G, Gazard Kindé D, Akogbéto M: The impact of the expansion of urban vegetable farming on malaria transmission in major cities of Benin. Parasit Vectors 2010, 3:118.

9. Plowe CV, Djimde A, Bouare M, Doumbo O, Wellems TE: Pyrimethamine and proguanil resistance-conferring mutations in Plasmodium falciparum dihydrofolate reductase: polymerase chain reaction methods for surveillance in Africa. Am J Trop Med Hyg 1995, 52:565-568.

10. Smythe JA, Peterson MG, Coppel RL, Saul AJ, Kemp DJ, Anders RF: Structural diversity in the 45- kilodalton merozoite surface antigen of Plasmodium falciparum. Mol Biochem Parasitol 1990, 39:227-234

11. Miller LH, Roberts T, Shahabuddin M, Mc Cutchan TF: Analysis of sequence diversity in the Plasmodium falciparum merozoite surface protein-1 (msp-1). Mol Biochem Parasitol 1993, 59:1-14.

12. Snounou G, Zhu X, Siripoon N, Jarra W, Thaithong S, Brown KN, Viriyakosol S: Biased distribution of msp1 and msp2 allelic variants in Plasmodium falciparum populations in Thailand. Trans R Soc Trop Med Hyg 1999, 93:369-377.

13. Djimdé A, Doumbo OK, Cortese JF, Kayentao K, Doumbo S, Diourté $Y$, Coulibaly D, Dicko A, Su XZ, Nomura T, Fidock DA, Wellems TE, Plowe CV: A molecular marker for chloroquine-resistant falciparum malaria. $N$ Engl J Med 2001, 344(supp|4):257-263.

14. Thomsen TT, Ishengoma DS, Mmbando BP, Lusingu JP, Vestergaard LS, Theander TG, Lemnge MM, Bygbjerg IC, Alifrangis M: Prevalence of single nucleotide polymorphisms in the Plasmodium falciparum multidrug resistance gene (Pfmdr-1) in Korogwe district in Tanzania before and after introduction of artemisinin-based combination therapy. Am J Trop Med Hyg 2011, 85:979-983.

15. Pearce R, Drakeley C, Chandramohan D, Mosha F, Roper C: Molecular determination of point mutation haplotypes in the dihydrofolate reductase and dihydropteroate synthase of Plasmodium falciparum in three districts of Northern Tanzania. Antimicrob Agents Chemother 2003, 47:1347-1354.

16. Mayengue PI, Ndounga M, Davy MM, Tandou N, Ntoumi F: In vivo chloroquine resistance and prevalence of the pfcrt codon 76 mutation in Plasmodium falciparum isolates from the Republic of Congo. Acta Trop 2007, 95:219-225.

17. Akogbeto M, Padonou GG, Bankole HS, Kinde Gazard D, Gbedjissi GL: Dramatic decrease in malaria transmission after large-scale indoor residual spraying with bendiocarb in Benin, an area of high resistance of Anopheles gambiae to pyrethroids. Am J Trop Med Hyg 2011, 85:586-593.

18. Soulama I, Nebie I, Ouedraogo A, Gansane A, Diarra A, Tiono AB, Bougouma EC, Konate A, Kabre GB, Taylor WRJ, Sirima SB: Plasmodium falciparum genotypes diversity in symptomatic malaria of children living in an urban and a rural setting in Burkina Faso. Malar J 2009, 8:135.

19. Issifou S, Djikou S, Sanni A, Lekoulou F, Ntoumi F: Pas d'influence de la saison de transmission ni de l'âge des patients sur la complexité et la diversité génétique des infections dues à Plasmodium falciparum à Cotonou (Bénin). Bull Soc Pathol Exot 2001, 94:195-198.

20. Aubouy A, Bakary M, Keundjian A, Mbomat B, Makita JR, Migot-Nabias F, Cot $M$, Le Bras J, Deloron P: Combination of drug level measurement and parasite genotyping data for an improved assessment of amodiaquine and sulfadoxine-pyrimethamine efficacy in treating Plasmodium falciparum malaria in Gabonese children. Antimicrob Agents Chemother 2003, 47:231-237.

21. Khaminsou N, Kritpetcharat O, Daduang J, Charerntanyarak L, Kritpetcharat P: Genetic analysis of the merozoite surface protein- 1 block 2 allelic types in Plasmodium falciparum clinical isolates from Lao PDR. Malar J 2011, 10:371. 
22. Bharti K, Shukla MM, Sharma YD, Singh N: Genetic diversity in the block 2 region of the merozoite surface protein-1 of Plasmodium falciparum in Central India. Malar J 2012, 11:78

23. Mayengue PI, Ndounga M, Davy MM, Tandou N, Ntoumi F: In vivo chloroquine resistance and prevalence of the pfcrt codon 76 mutation in Plasmodium falciparum isolates from the Republic of Congo. Acta Trop 2005, 95(suppl3):219-225.

24. Mayengue Pl, Ndounga M, Malonga FV, Bitemo M, Ntoumi F: Genetic polymorphism of merozoite surface protein-1 and merozoite surface protein-2 in Plasmodium falciparum isolates from Brazzaville, Republic of Congo. Malar J 2011, 10:276.

25. Yuan L, Zhao H, Wu L, Li X, Parker D, Xu S, Zhao Y, Feng G, Wang Y, Yan G, Fan Q, Yang Z, Cui L: Plasmodium falciparum populations from northeastern Myanmar display high levels of genetic diversity at multiple antigenic loci. Acta Trop 2013, 125:53-59.

26. Soulama I, Sawadogo M, Nebie I, Diarra A, Tiono AB, Konate A, Sirima SB: Diversité génétique de Plasmodium falciparum et pathogénie de I' anémie palustre sévère chez des enfants de moins de 5 ans de la province du Boulgou, Burkina Faso. Bull Soc Pathol Exot 2006, 99:166-170.

27. Vafa M, Troye-Blomberg M, Anchang J, Garcia A, Migot-Nabias F: Multiplicity of Plasmodium falciparum infection in asymptomatic children in Senegal: relation to transmission, age and erythrocyte variants. Malar J 2008, 7:17.

28. Ojurongbe O, Fagbenro-Beyioku AF, Adeyeba OA, Kun JF: Allelic diversity of merozoite surface protein 2 gene of $P$. falciparum among children in Osogbo, Nigeria. West Indian Med J 2011, 60:19-23.

29. Koukouikila-Koussounda F, Malonga V, Mayengue PI, Ndounga M, Vouvoungui CJ, Ntoumi F: Genetic polymorphism of merozoite surface protein 2 and prevalence of K76T pfcrt mutation in Plasmodium falciparum field isolates from Congolese children with asymptomatic infections. Malar J 2012, 11:105.

30. Duah NO, Quashie NB, Abuaku BK, Sebeny PJ, Kronmann KC, Koram KA: Surveillance of molecular markers of Plasmodium falciparum resistance to sulphadoxine-pyrimethamine 5 years after the change of malaria treatment policy in Ghana. Am Soc Trop Med Hyg 2012, 87:996-1003.

31. Sisowath C, Strömberg J, Martensson A, Msellem M, Obondo C, Björkman A, Gil JP: In vivo selection of Plasmodium falciparum pfmdr1 $86 \mathrm{~N}$ codingalleles by artemether-lumefantrine (Coartem). J Infect Dis 2005, 191:1014-1021.

32. Thomsen TT, Madsen LB, Hansson HH, Tomas EV, Charlwood D, Bygbjerg IC, Alifrangis M: Rapid selection of Plasmodium falciparum chloroquine resistance transporter gene and multidrugresistance gene-1 haplotypesassociatedwithpast chloroquine and presentartemether-lumefantrine use in Inhambane District, Southern Mozambique. Am J Trop Med Hyg 2013, 88:536-541.

33. Organisation Mondiale de la Santé: Surveillance de la résistance aux antipaludiques. Rapport d'une consultation de l'OMS Genève, Suisse, 3-5 décembre 2001. WHO/CDS/CSR/EPH/2002.17/WHO/CDS/RBM/2002.39: http:// whqlibdoc.who.int/hq/2002/who_cds_csr_eph_2002.17_fre.pdf.

34. Babiker HA, Pringle SJ, Abdel-Muhsin A, Mackinnon M, Hunt P, Walliker D: High-level chloroquine resistance in Sudanese isolates of Plasmodium falciparum is associated with mutations in the chloroquine-resistance transporter gene pfort and the multidrug resistance Gene pfmdr1. $J$ Infect Dis 2001, 183:1535-1538.

35. Kublin JG, Dzinjalamala FK, Kamwendo DD, Malkin EM, Cortese JF, Martino LM, Mukadam RAM, Rogerson SJ, Lescano AG, Molyneux ME, Winstanley PA, Chimpeni P, Taylor TE, Plowe CV: Molecular markers for failure of sulfadoxine-pyrimethamine and chlorproguanil-dapsone treatment of Plasmodium falciparum malaria. J Infect Dis 2002, 185:380-388.

36. Omar SA, Adagu IS, Warhurst DC: Can pretreatment screening for dhps and dhfr point mutations in Plasmodium falciparum infections be used to predict sulfadoxine-pyrimethamine treatment failure? Trans $R$ Soc Trop Med Hyg 2001, 95:315-319.

37. Steadke SG, Sendagire H, Lamola S, Kamya MR, Dorsey G, Rosenthal PJ: Relationship between age, molecular markers, and response to sulphadoxine-pyrimethamine treatment in Kampala, Uganda. Trop Med Int Health 2004, 9(suppl5):624-629.

38. Dicko A, Sagara I, Djimdé AA, Touré SO, Traore M, Dama S, Diallo Al, Barry A, Dicko M, Coulibaly OM, Rogier C, de Sousa A, Doumbo OK: Molecular markers of resistance to sulphadoxine-pyrimethamine one year after implementation of intermittent preventive treatment of malaria in infants in Mali. Malar J 2010, 9:9.
39. Faye B, Ndiaye M, Ndiaye $U$, Annie A, Tine RC, Lo AC, Sow D, De Sousa A, Gaye O: Prevalence of molecular markers of Plasmodium falciparum resistance to sulfadoxine-pyrimethamine during the intermittent preventive treatment in infants coupled with the expanded program immunization in Senegal. Parasitol Res 2011, 109:133-138.

40. Ojurongbe O, Ogungbamigbe TO, Fagbenro-Beyioku AF, Fendel R, Kremsner PG, Kun JFJ: Rapid detection of Pfcrt and Pfmdr1 mutations in Plasmodium falciparum isolates by FRET and in vivo response to chloroquine among children from Osogbo, Nigeria. Malar J 2007, 6:41.

doi:10.1186/1475-2875-12-413

Cite this article as: Ogouyèmi-Hounto et al:: Low prevalence of the molecular markers of Plasmodium falciparum resistance to chloroquine and sulphadoxine/pyrimethamine in asymptomatic children in Northern Benin. Malaria Journal 2013 12:413.

\section{Submit your next manuscript to BioMed Central and take full advantage of:}

- Convenient online submission

- Thorough peer review

- No space constraints or color figure charges

- Immediate publication on acceptance

- Inclusion in PubMed, CAS, Scopus and Google Scholar

- Research which is freely available for redistribution 